\section{A Place for Radiofrequency Ablation in the Treatment of Resectable Colorectal Liver Metastases?}

\author{
To the Editor:
}

With great interest we read the exhaustive review "Radiofrequency Ablation versus Resection for Resectable Colorectal Liver Metastases: Time for a Randomized Trial?"" in which Mulier et al. clearly summarizes the literature regarding radiofrequency ablation (RFA) as a treatment option for colorectal liver metastases (CRLM). The authors propose arguments and criteria for a noninferiority trial comparing RFA and resection for resectable CRLM with 5year survival as a main outcome. However, we believe that they compare apples and oranges in their review of literature. In accordance with the Editorial by Curley, ${ }^{2}$ we do not think it is time for a randomized trial for resectable lesions yet.

There is the main problem of defining the effectiveness of the technique. We agree with their statement that RFA should only be attempted when complete eradication of the tumor including a safety margin is possible, but review of the available data is debatable as different definitions of technique effectiveness are being used. ${ }^{3}$ How should we manage lesions being treated with RFA that show hypervascularity at the periphery in follow-up? Should we perform a second RFA treatment, or a resection as rescue therapy? One has to study the outcome of incompletely RFA treated lesions that necessitate additional intervention either by RFA or surgery. Patients should be well informed that they might need a second intervention after initial treatment failure. As results from pathologic examination of larger series are currently lacking, well-defined local failure (incompletely ablated tumor tissue that continues to grow) and local recurrence rates (new tumor foci growing at the original ablated site) ${ }^{4}$ and their outcome remain to be established before RFA can challenge resection in a randomized trial.

In the proposed trial, the authors suggest a surgical RFA approach. According to our results and those of others, the surgical approach appears to be superior to the percutaneous route in achieving local control, ${ }^{4}$ and it is clear that the open approach offers the advantage of direct examination for extrahepatic intra-abdominal disease. An extra-anatomic liver resection, however, will not have a much higher morbidity than a RFA during laparotomy. Is it ethical to assign patients to open RFA as the first choice treatment? Do we really need to compare both modalities and study long-term survival in this particular patient group, or should we reserve RFA for patients unable to tolerate surgery?

If there is a favorable effect of RFA on long-term survival, the biochemical and genetic background should be first established. Identification of factors predicting the outcome by genomic and proteomic analyses may help to differentiate between patients who should be managed most aggressively and those who may benefit from minimal invasive techniques. In Rotterdam, we are currently performing such a prospective controlled study including more than 1000 patients with colorectal cancer.

Until then, the use of RFA as a treatment modality for resectable CRLM should be restricted to high-volume, experienced hepatobiliary centers with a multidisciplinary approach. In the era of evidence-based medicine, we emphasize the need for proper prospective data collection and advocate standardized treatment and imaging algorithms to justify the experimental use of RFA when applied instead of, or in addition to, hepatic resection.

V. E. de Meijer, MD, MSc, and J. N. M. IJzermans, MD, $\mathrm{PhD}$, Erasmus MC-University Medical Center Rotterdam Rotterdam

The Netherlands e-mail: j.ijzermans@erasmusmc.nl

C. Verhoef, MD, Daniel den Hoed Cancer Clinic Rotterdam

The Netherlands

\section{OPEN ACCESS}

This article is distributed under the terms of the Creative Commons Attribution Noncommercial License which permits any noncommercial use, distribution, and reproduction in any medium, provided the original author(s) and source are credited.

\section{REFERENCES}

1. Mulier S, Ni Y, Jamart J, et al. Radiofrequency ablation versus resection for resectable colorectal liver metastases: Time for a randomized trial? Ann Surg Oncol 2008; 15:144-57.

2. Curley SA. Radiofrequency ablation versus resection for resectable colorectal liver metastases: Time for a randomized trial? Ann Surg Oncol 2008; 15:11-3.

3. Goldberg SN, Grassi CJ, Cardella JF, et al. Image-guided tumor ablation: Standardization of terminology and reporting criteria. Radiology 2005; 235:728-39.

4. de Meijer VE, Verhoef C, Kuiper JW, et al. Radiofrequency ablation in patients with primary and secondary hepatic malignancies. J Gastrointest Surg 2006; 10:960-73.

Published online March 8, 2008. DOI: $10.1245 / \mathrm{s} 10434-008-9843-\mathrm{Z}$ 